\title{
Petrofísica de Folhelhos Negros da Bacia do Araripe
}

José Agnelo Soares ${ }^{1}$; Juliana Targino Batista ${ }^{1}$; Caroline Henrique Dias ${ }^{2}$

'Universidade Federal de Campina Grande, ${ }^{2}$ UFRJ/COPPE/LAB2M

Copyright 2016, SBGf - Sociedade Brasileira de Geofísica

Este texto foi preparado para a apresentação no VII Simpósio Brasileiro de Geofísica Ouro Preto, 25 a 27 de outubro de 2016. Seu conteúdo foi revisado pelo Comitê Técnico do VII SimBGf, mas não necessariamente representa a opinião da SBGf ou de seus associados. E proibida a reprodução total ou parcial deste material para propósitos comerciais sem prévia autorização da SBGf.

\section{Resumo}

Este trabalho apresenta os valores de porosidade, de densidade de grãos e total e de velocidades elásticas medidas em amostras de folhelhos negros da Bacia do Araripe. Devido à saturação natural em petróleo, os valores medidos de porosidade e de densidade são aparentes. Neste trabalho é proposto um método para a estimativa da saturação de óleo e das propriedades petrofísicas reais. Os resultados obtidos mostraram que a porosidade verdadeira, a saturação de óleo e a velocidade acústica da matriz dependem, principalmente e de forma decrescente, do valor da densidade de grãos.

\section{Introdução}

A Bacia do Araripe está localizada no Nordeste do Brasil, entre os lineamentos de Patos e Pernambuco. É uma extensa bacia interior dominada pela Chapada do Araripe e que também compreende a região do Vale do Cariri. Seus limites se estendem pelos estados do Ceará, Piauí, Pernambuco e Paraíba numa área de aproximadamente $10.000 \mathrm{~km}^{2}$ (Figura 1). O Andar Alagoas na Bacia do Araripe é composto pelas formações Barbalha e Santana. A Formação Santana se subdivide nos membros Crato (inferior) e Membro Romualdo (superior). O Membro Crato é constituído por bancos de calcários laminados intercalados com folhelhos, siltitos e arenitos. Cinco camadas carbonáticas distintas ocorrem no Membro Crato, com espessuras variadas, intercaladas com camadas de folhelhos negros, ricos em matéria orgânica, folhelhos verdes e arenitos (Assine, 1992).

Os folhelhos negros do Araripe corespondem a laminitos negros depositados em ambiente redutor no interior de lagos. Neumann et al (2003) mostraram que os folhelhos negros exibem teores variados de carbonatos e teores de carbono orgânico entre $5 \%$ e $19 \%$. Esta fácies contém abundante matéria orgânica derivada de bactérias e algas e encontrada na forma de lamalginita bem a pobremente preservada. Lamalginita é um componente orgânico tipicamente encontrado em depósitos lacustres ricos em matéria orgânica. $O$ estudo da maturidade da matéria orgânica das sequências lacustres AptianaAlbiana da Bacia do Araripe mostra um grau de maturidade muito baixo para a geração de óleo. A matéria orgânica dos follhelhos negros se mostrou rica em hidrogênio e com valores nulos de reflectância.

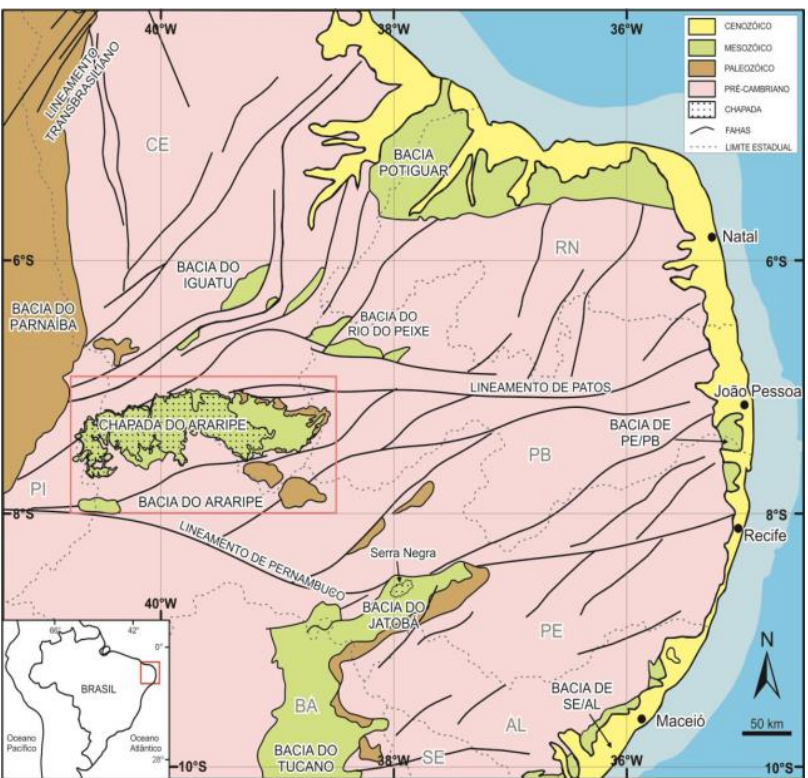

Figura 1 - Mapa de localização com destaque, em vermelho, para a Bacia do Araripe (extraído de Catto, 2015).

Em trabalho de campo foram coletadas 21 amostras de folhelho negro em um afloramento localizado em uma mina localizada nas cercanias da cidade de Nova Olinda, no estado do Ceará. As amostras verticais foram extraídas de blocos disponíveis na frente de lavra, enquanto que as amostras horizontais foram extraídas da parede vertical da frente de lavra. A Figura 2 apresenta uma fotografia do afloramento.

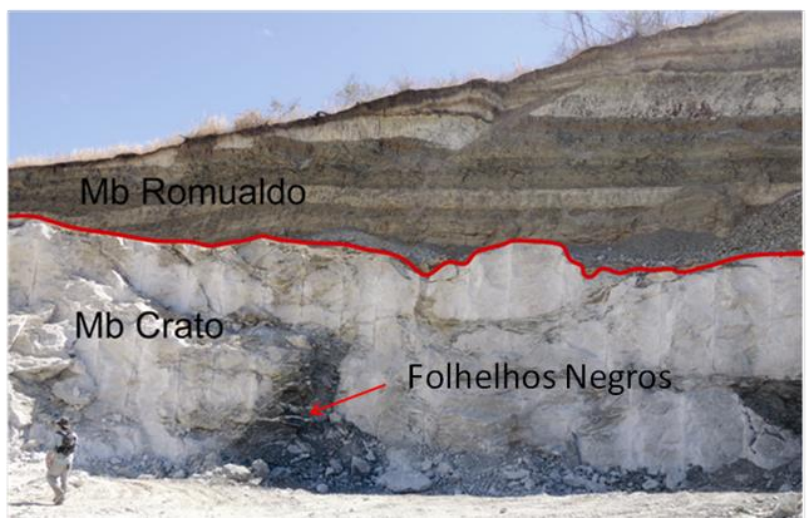

Figura 2 - Fotografia da frente de lavra da mina de onde foram extraídas as amostras de folhelho negro. 


\section{Análises Laboratoriais}

Após a pesagem e medição das dimensões dos plugues, foram realizados os ensaios no permoporosímetro a gás. Com o uso do matrix cup mede-se o volume de grãos do plugue. A diferença entre o volume de grãos e o volume total consiste no volume de vazios da amostra. A porosidade é determinada pela razão entre o volume de vazios e o volume total. Assumindo-se que a massa da amostra corresponde à massa de sua fase sólida, a densidade de grãos é dada pela razão entre a massa do plugue e o volume de grãos medido. Com a porosidade e a densidade de grãos pode-se estimar a densidade total da rocha desprezando a densidade do ar que preenche os poros da rocha. $O$ volume de grãos é medido pela expansão do nitrogênio contido em uma câmara no interior do permoporosímetro.

Os ensaios de propriedades elásticas foram realizados através da medição do tempo de trânsito da transmissão direta de ondas $\mathrm{P}$ e $\mathrm{S}$ através do comprimento axial dos plugues analisados. O equipamento Autolab500 ${ }^{\circledR}$ permite realizar ensaios sob condições controladas de pressão confinante, de poros, temperatura e saturação fluida. Neste trabalho as medições das velocidades das onda $P$ e $S$ foram realizadas em plugues saturados naturalmente por petróleo e submetidos a níveis decrescentes de pressão confinante. A pressão de poros e a temperatura foram mantidas nos níveis do ambiente. Determinados os tempos de trânsito das ondas e conhecidos os comprimentos dos plugues, as velocidades de propagação das ondas são dadas pela razão entre estes parâmetros. As velocidades elásticas foram medidas sob pressão efetiva entre 5 e $20 \mathrm{MPa}$ e a porosidade foi medida a pressão ambiente.

A partir das velocidades de propagação das ondas $P$ e $S$ e da densidade total dos plugues, calculam-se os módulos elásticos: módulo de elasticidade (E), incompressibilidade $(K)$, módulo de cisalhamento $(G)$ e razão de Poisson (v).

\section{Efeito da saturação parcial em petróleo}

Uma vez que as amostras de folhelho se encontravam parcialmente saturadas com petróleo de ocorrência natural, as propriedades petrofísicas medidas não apresentaram os valores e as relações esperadas.

Com o objetivo de avaliar as propriedades petrofísicas reais, propõe-se neste trabalho, um modelo petrofísico para a interpretação de folhelhos parcialmente saturados com petróleo.

A equação (1) estabelece a relação entre a porosidade aparente $\left(\emptyset_{A}\right)$, a saturação de óleo (So) e a porosidade real $\left(\emptyset_{R}\right)$.

$$
\phi_{\mathrm{R}}=\frac{\phi_{\mathrm{A}}}{\left(1-\mathrm{S}_{\mathrm{O}}\right)}
$$

Sabendo-se que a densidade total $\left(\rho_{\mathrm{B}}\right)$ é dada pela soma de um termo relativo à densidade real de grãos $\left(\rho_{\mathrm{GR}}\right)$ e outro relacionado à densidade $\left(\rho_{0}\right)$ e saturação (So) do óleo, e que o termo relativo à densidade do ar pode ser desprezado, temos a equação (2).

$$
\rho_{B}=\rho_{G R}\left(1-\phi_{R}\right)+\rho_{o} S_{o} \phi_{R}
$$

Manipulando a equação (2) para explicitar a saturação de óleo, chega-se a equação (3).

$$
S_{\mathrm{o}}=\frac{\rho_{\mathrm{GR}}\left(1-\phi_{\mathrm{A}}\right)-\rho_{\mathrm{B}}}{\rho_{\mathrm{GR}}-\rho_{\mathrm{O}} \phi_{\mathrm{A}}-\rho_{\mathrm{B}}}
$$

A fim de corrigir o efeito da saturação parcial de óleo sobre as velocidades elásticas, adotou-se a Equação de Wyllie:

$$
\frac{1}{V_{P}}=\frac{\phi_{R}}{V_{F}}+\frac{\left(1-\phi_{R}\right)}{V_{M A}}
$$

Onde $\emptyset_{R}$ é a porosidade real, $V_{P}$ é a velocidade da onda $P$ medida na amostra, $V_{M A}$ é a velocidade da matriz mineral e $V_{F}$ é a velocidade no fluido saturante. Explicitando a velocidade da matriz:

$$
\mathrm{V}_{\mathrm{MA}}=\frac{\left(1-\phi_{\mathrm{R}}\right) \mathrm{V}_{\mathrm{F}} \mathrm{V}_{\mathrm{P}}}{\mathrm{V}_{\mathrm{F}}-\phi_{\mathrm{R}} \mathrm{V}_{\mathrm{P}}}
$$

A velocidade da onda $P$ no fluido é dada em função das proporções de óleo e ar que compõem esse fluido e das incompressibilidades do óleo e do ar. Para o cálculo das incompressibilidades é necessário conhecer as velocidades e as densidades das fases que compõem o fluido.

A velocidade da onda $P$ no óleo, em função da densidade, pressão e temperatura, de acordo com Batzle e Wang (1992), é dada por:

$$
\begin{aligned}
& V_{P}=15450(77,1+\mathrm{API})^{-0,5}-3,7 \mathrm{~T}+ \\
& +4,64 \mathrm{P}+0,0115\left(0,36 \mathrm{API}^{0,5}-1\right) \mathrm{TP}
\end{aligned}
$$

Onde $V_{P}$ é dado em $\mathrm{m} / \mathrm{s}$, $T$ em $\stackrel{\circ}{ } \mathrm{C}$ e $\mathrm{P}$ em MPa. $A$ densidade do óleo adotada variou entre 0,8 e $0,9 \mathrm{~g} / \mathrm{cm}^{3}$ e a pressão adotada foi de $20 \mathrm{MPa}$. Para a fase preenchida por ar foi adotada uma velocidade da onda $P$ de $350 \mathrm{~m} / \mathrm{s}$ e uma densidade de $1,3 \mathrm{~kg} / \mathrm{m}^{3}$.

Para o cálculo da incompressibilidade do fluido foi utilizado o modelo patchy saturation (Mavko et al., 2003), o qual prevê que a incompressibilidade e a densidade de uma mistura fluida, no interior dos poros de uma rocha, é dada por:

$$
\begin{aligned}
\mathrm{K}_{\mathrm{F}} & =\mathrm{S}_{\mathrm{O}} \mathrm{K}_{\mathrm{o}}+\mathrm{S}_{\mathrm{ar}} \mathrm{K}_{\mathrm{ar}} \\
\rho_{\mathrm{F}} & =\mathrm{S}_{\mathrm{O}} \rho_{\mathrm{O}}+\mathrm{S}_{\mathrm{ar}} \rho_{\mathrm{ar}}
\end{aligned}
$$

$A V_{F}$ é dada pela raiz quadrada da razão entre $K_{F}$ e $\rho_{F}$.

\section{Resultados}

A Figura 3 apresenta os valores medidos para a densidade de grãos e para a porosidade. Devido ao fato das amostras apresentarem saturação parcial de hidrocarbonetos, as propriedades medidas são 
classificadas como propriedades aparentes. Normalmente não existe correlação entre densidade de grãos e porosidade. No entanto, uma maior saturação de óleo provoca uma maior redução no valor da porosidade e na densidade de grãos, a qual também é afetada pela presença de matéria orgânica. Este efeito pode ser utilizado para o cálculo da saturação de óleo.

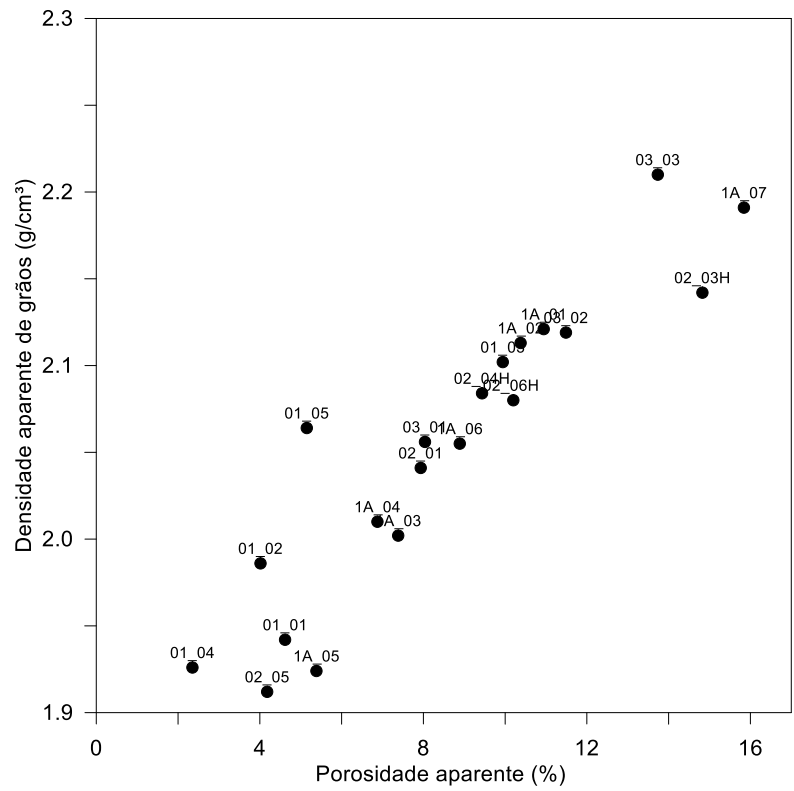

Figura 3 - Densidade de grãos e porosidade medidas.

A Figura 4 apresenta a relação entre a densidade total e a porosidade aparente das amostras. Normalmente há uma relação inversa entre essas duas propriedades. No entanto, o que se observa na Figura 4 é que não há qualquer relação entre essas propriedades para as amostras analisadas.

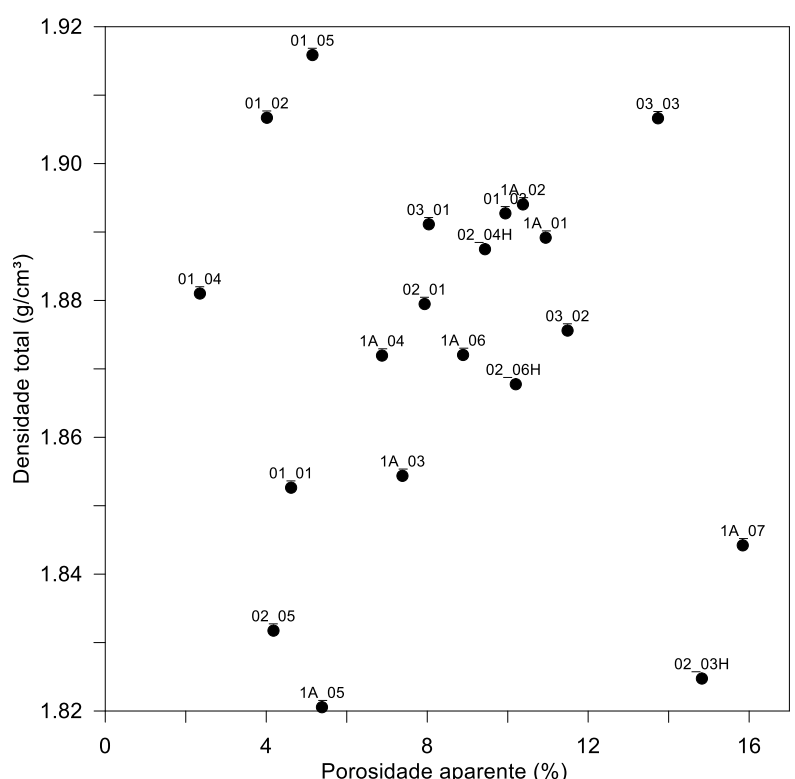

Figura 4 - Relação entre densidade total e porosidade aparente.
As Figuras 5 e 6 apresentam as velocidades das ondas $P$ e $S_{1}$, respectivamente, contra a pressão confinante. As velocidades foram medidas a pressões decrescentes. $\mathrm{Na}$ Figura 5 observam-se três grupos de amostras: o grupo de maior velocidade corresponde às amostras horizontais, o grupo de amostras de menor velocidade é composto pelas amostras de maior saturação de óleo, como será demonstrado adiante. Já na Figura 6 não se observa essa separação por grupos de velocidade, uma vez que a velocidade da onda $S$ não é afetada pela saturação fluida. Comportamento semelhante foi observado para a velocidade da onda $\mathrm{S}_{2}$.

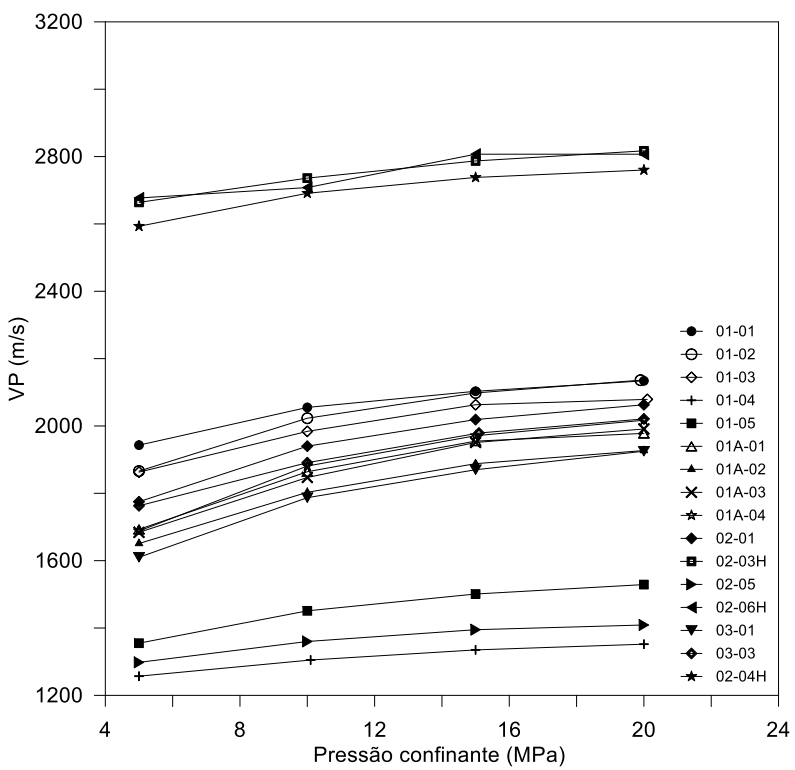

Figura 5 - Velocidade da onda $P$ versus a pressão confinante.

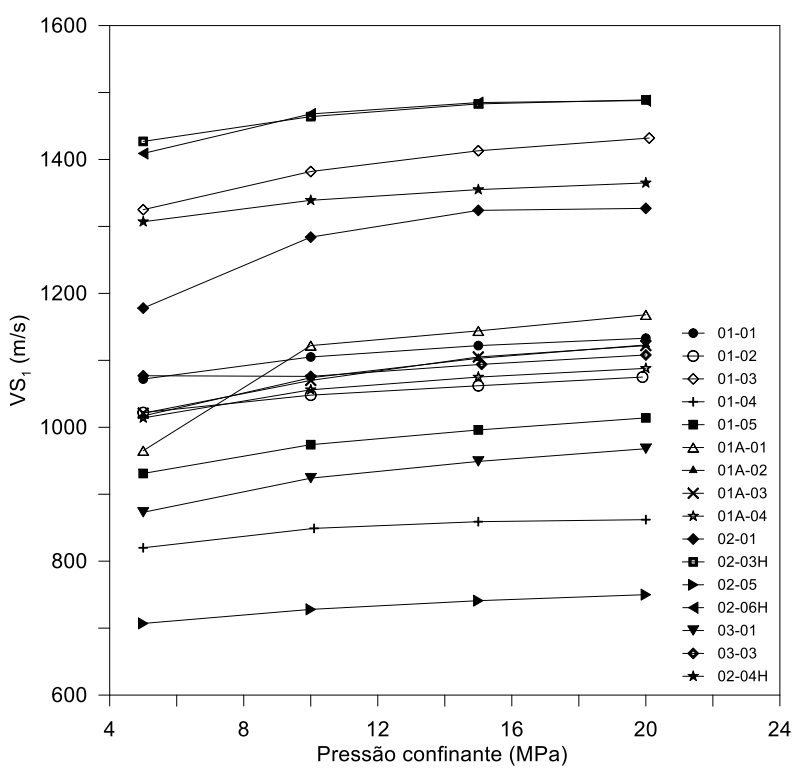

Figura 6 - Velocidade da onda $V S_{1}$ versus a pressão confinante. 
A Figura 7 apresenta a razão entre as velocidades das duas ondas S. Quanto mais o valor dessa razão se afasta da unidade, maior é a anisotropia da rocha. Desta figura vê-se que há um grupo de amostras com anisotropia muito baixa e outro grupo com anisotropia mediana.

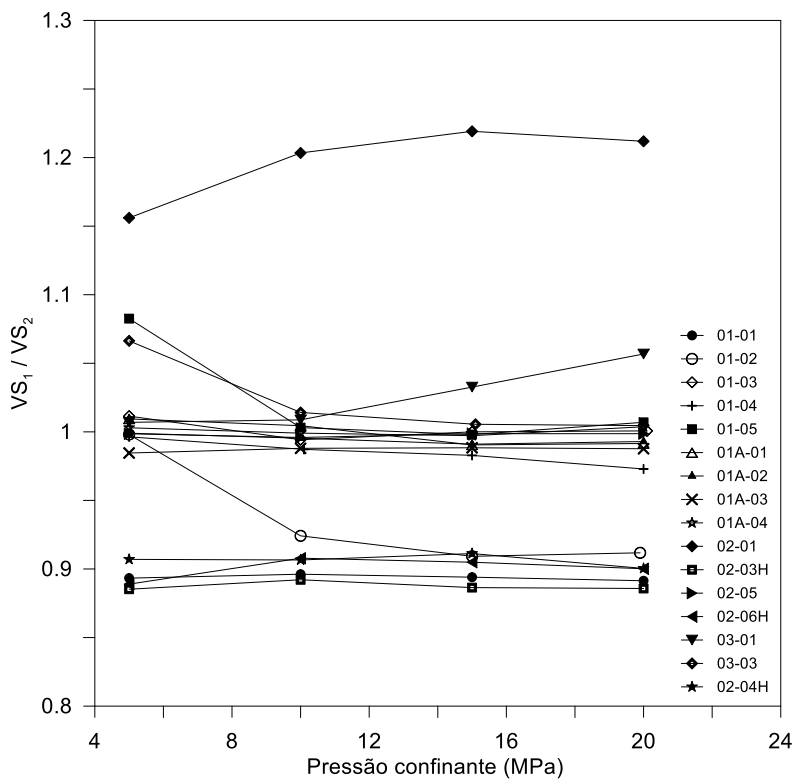

Figura 7 - Razão entre as velocidades das ondas $S$ versus a pressão confinante.

As Figuras 8 e 9 apresentam a relação entre as velocidades das ondas $\mathrm{P}$ e $\mathrm{S}_{1}$, respectivamente, medidas a $20 \mathrm{MPa}$, contra a porosidade aparente. Esperam-se relações inversas entre as velocidades elásticas e a porosidade. Devido à saturação parcial de hidrocarbonetos esse comportamento não é observado.

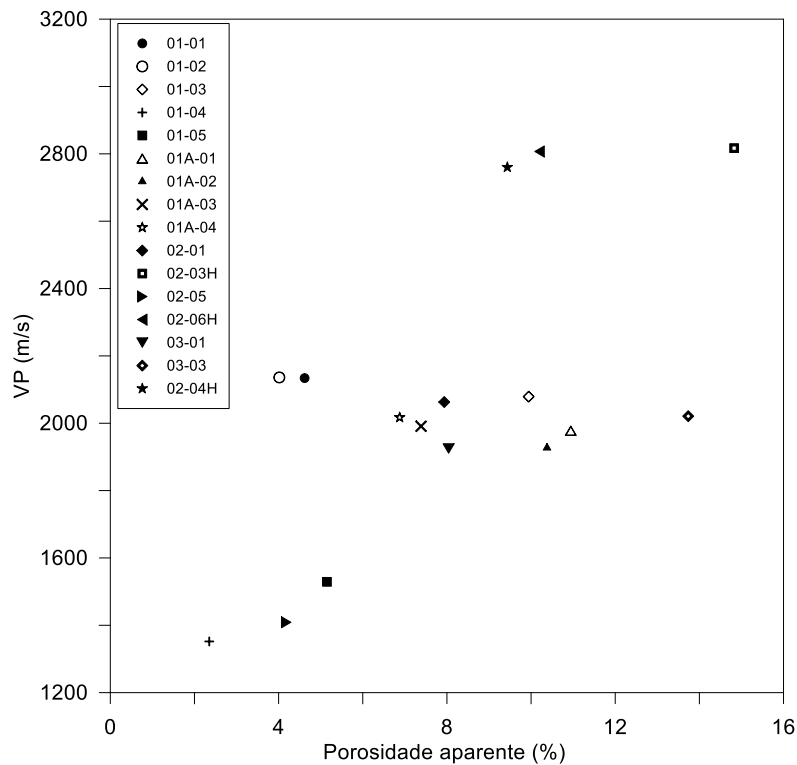

Figura 8 - Velocidade da onda P medida sob $20 \mathrm{MPa}$ versus a porosidade aparente.

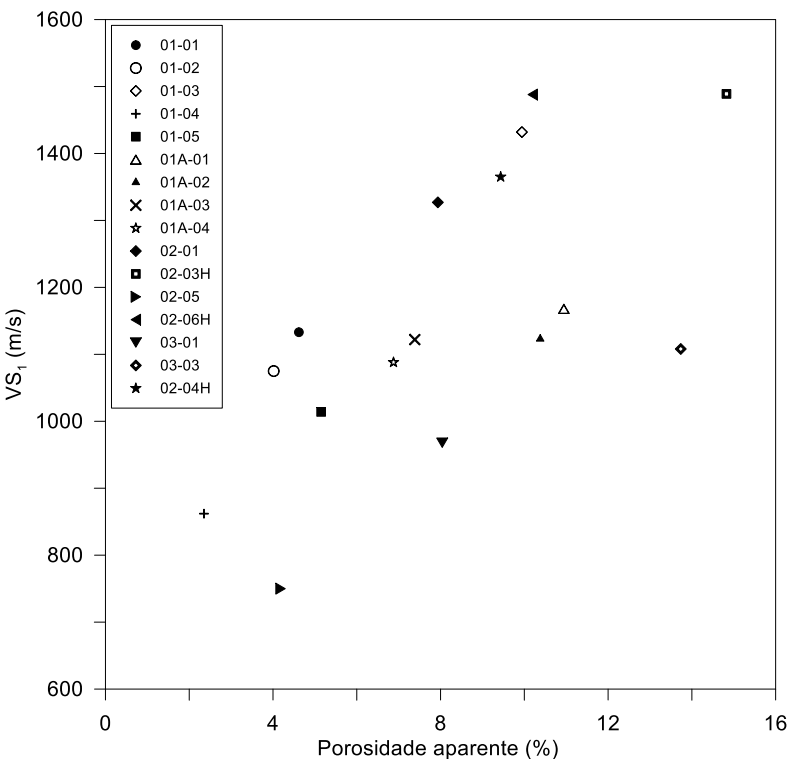

Figura 9 - Velocidade da onda $S_{1}$ medida sob $20 \mathrm{MPa}$ versus a porosidade aparente.

As equações (1) a (4) governam as relações entre as propriedades petrofísicas reais e aquelas medidas com as amostras parcialmente saturadas por petróleo. Estas quatro equações apresentam seis incógnitas $\left(\phi_{R}, S_{o}, \rho_{G R}\right.$, $\rho o, V_{F}$ e $V_{M A}$ ), de modo que esse sistema de equações é subdeterminado. No entanto, $\rho_{G R}$ (densidade real de grãos) e $\rho o$ (densidade do óleo) são as duas incógnitas que menos variam, de modo que se pode simular o efeito da variação desses parâmetros sobre as demais variáveis. A Figura 10 apresenta a estimativa da saturação de óleo considerando $\rho \circ=0,85 \mathrm{~g} / \mathrm{cm}^{3}$ e variando $\rho_{\mathrm{GR}}$ entre 2,4 e $2,6 \mathrm{~g} / \mathrm{cm}^{3}$.

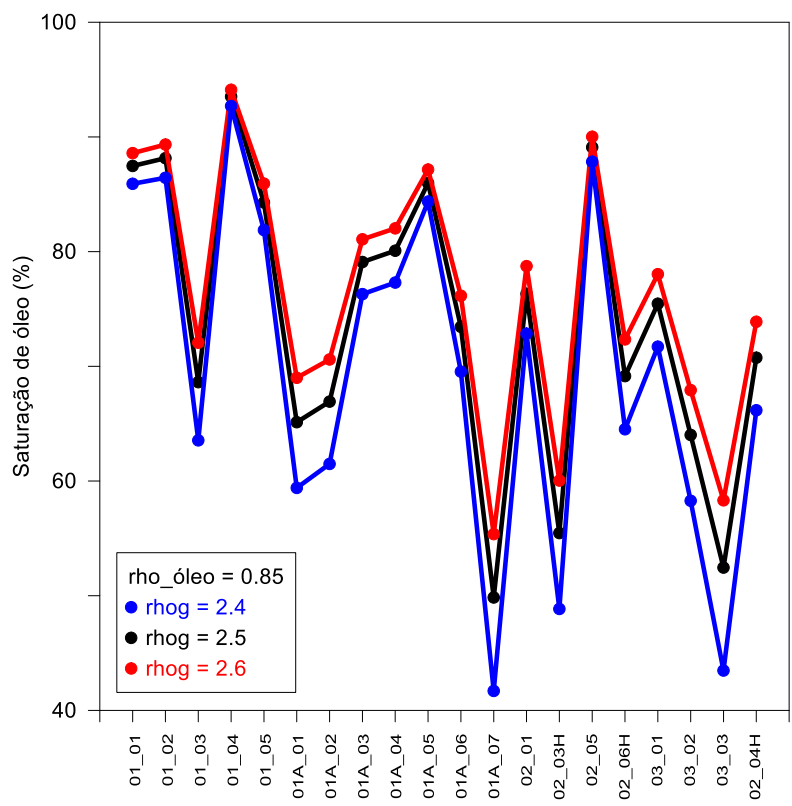

Figura 10 - Saturação de óleo estimada considerando $\rho_{\mathrm{O}}=0,85 \mathrm{~g} / \mathrm{cm}^{3}$ e variando $\rho_{\mathrm{GR}}$ entre 2,4 e $2,6 \mathrm{~g} / \mathrm{cm}^{3}$. 
Na Figura 11 testa-se o efeito da variação da densidade do óleo, fixando o valor de $\rho_{G R}$ em $2,5 \mathrm{~g} / \mathrm{cm}^{3}$.

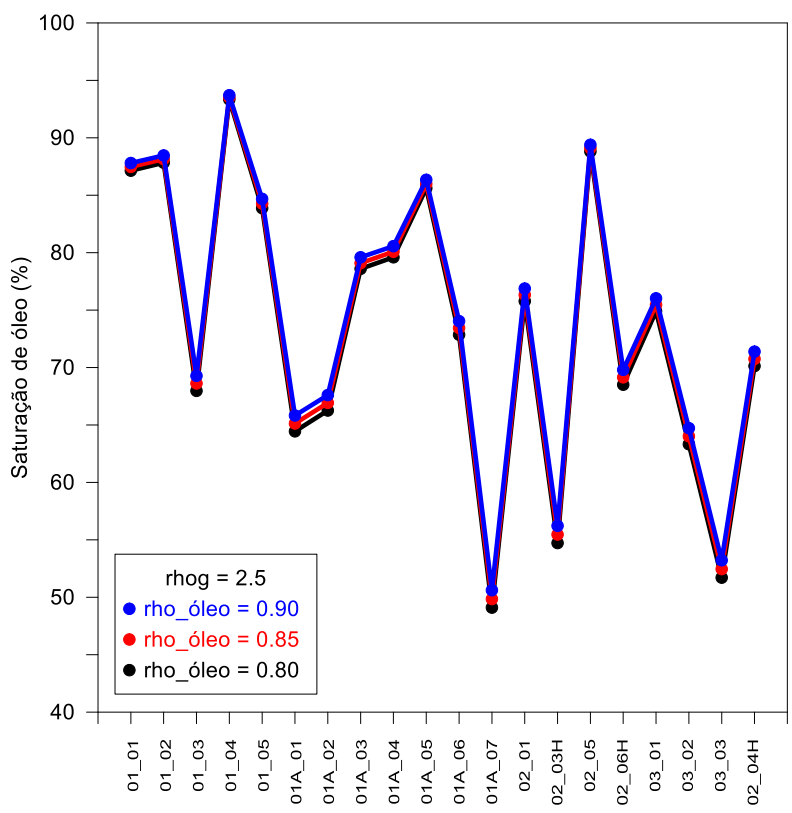

Figura 11 - Saturação de óleo estimada considerando $\rho_{\mathrm{GR}}=2,5 \mathrm{~g} / \mathrm{cm}^{3}$ e variando $\rho_{\mathrm{O}}$ entre 0,8 e $0,9 \mathrm{~g} / \mathrm{cm}^{3}$.

Nota-se, das figuras 10 e 11, que a estimativa da saturação de óleo é pouco dependente de $\rho_{0}$ e que varia mais com $\rho \mathrm{GR}$, especialmente para as amostras com menor saturação de óleo.

Nas figuras 12 e 13 são apresentados os valores reais de porosidade fazendo variar, respectivamente, os valores de densidade de grãos e do óleo. Nota-se que a estimativa da porosidade real é mais sensível à variação desses parâmetros, principalmente em relação à $\rho_{\mathrm{GR}}$.

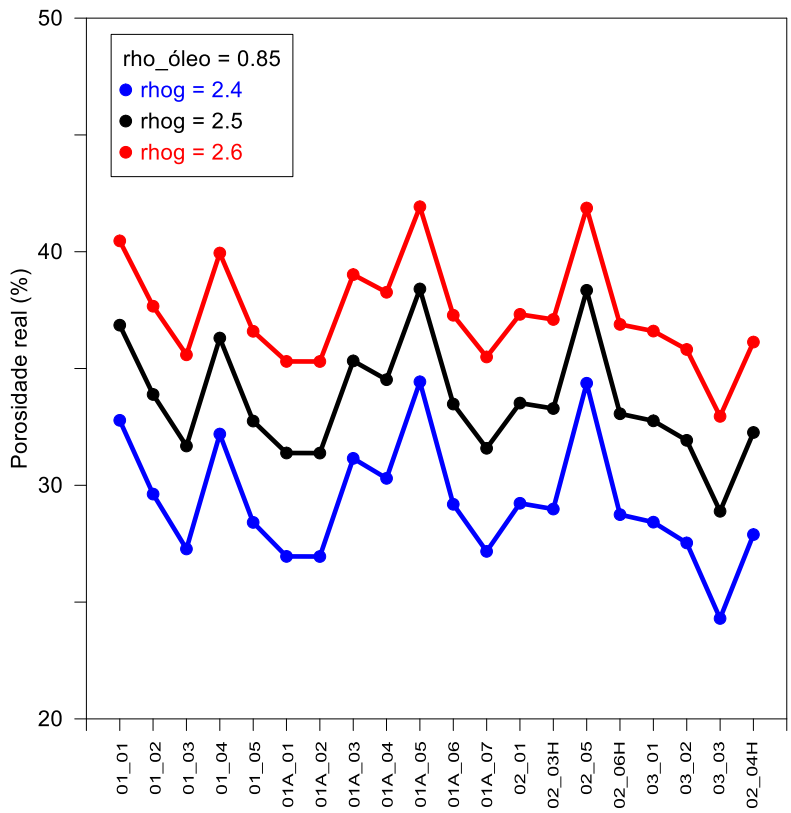

Figura 12 - Porosidade real estimada considerando $\rho_{0}=$ $0,85 \mathrm{~g} / \mathrm{cm}^{3}$ e variando $\rho_{\mathrm{GR}}$ entre 2,4 e $2,6 \mathrm{~g} / \mathrm{cm}^{3}$.

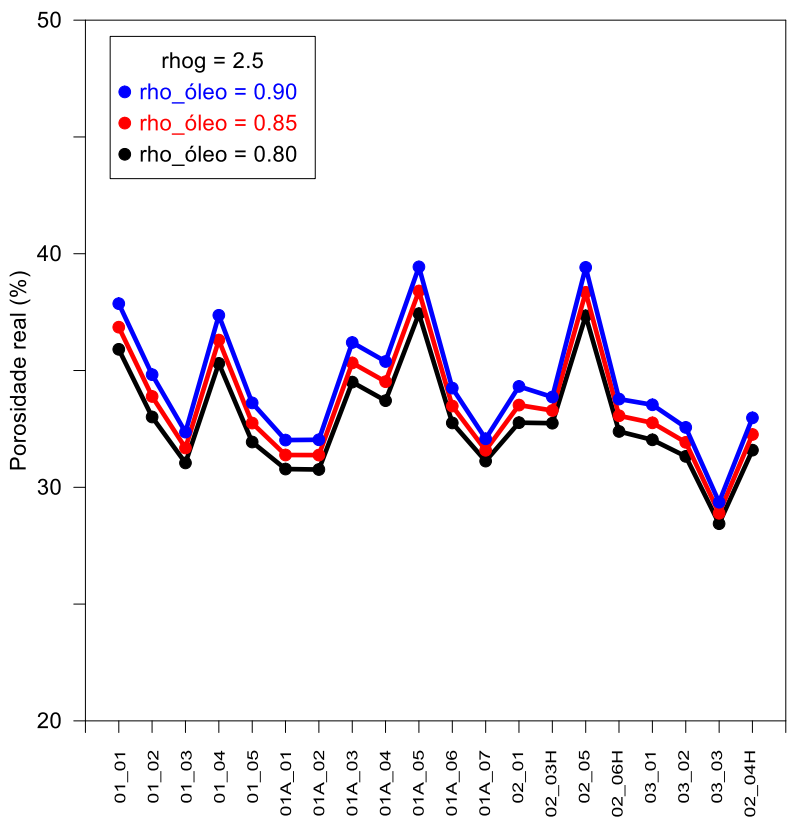

Figura 13 - Saturação de óleo estimada considerando $\rho_{\mathrm{GR}}=2,5 \mathrm{~g} / \mathrm{cm}^{3}$ e variando $\rho_{0}$ entre 0,8 e $0,9 \mathrm{~g} / \mathrm{cm}^{3}$.

A Figura 14 apresenta a velocidade da onda $P$ estimada para a matriz mineral das amostras de folhelho, sob 20 $\mathrm{MPa}$, considerando uma densidade real de grãos igual a $2,5 \mathrm{~g} / \mathrm{cm}^{3}$ e fazendo variar a densidade do óleo entre 0,8 e $0,9 \mathrm{~g} / \mathrm{cm}^{3}$. Observa-se que a VP da matriz é quase insensível ao valor da densidade do óleo, especialmente para as amostras de menor VP da matriz. As três amostras de maior VP da matriz são as amostras horizontais e as três que apresentam os menores valores são supostamente amostras mais ricas em matéria orgânica ou em uma fase mineral de baixa velocidade.

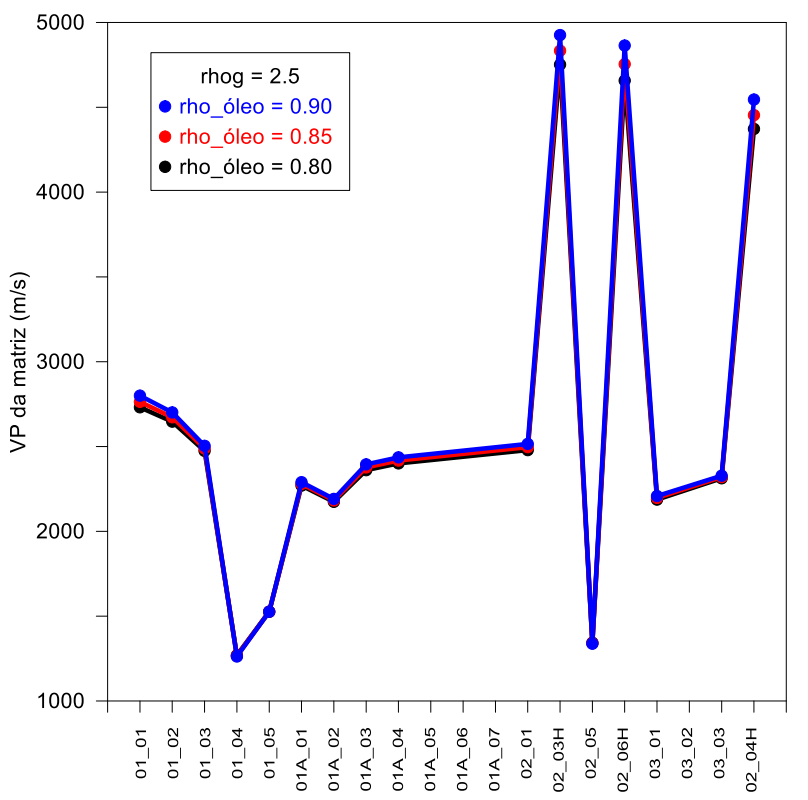

Figura 14 - Estimativa da VP da matriz considerando $\rho_{\mathrm{GR}}=2,5 \mathrm{~g} / \mathrm{cm}^{3}$ e variando $\rho_{\mathrm{O}}$ entre 0,8 e $0,9 \mathrm{~g} / \mathrm{cm}^{3}$. 
A Figura 15 analisa o efeito da densidade real de grãos sobre a VP da matriz. Neste caso a pressão confinante é de $20 \mathrm{MPa}$ e a densidade do óleo é igual a 0,85 $\mathrm{g} / \mathrm{cm}^{3}$. Para as amostras de maior velocidade vê-se uma dependência considerável da VP da matriz em relação à densidade real de grãos.

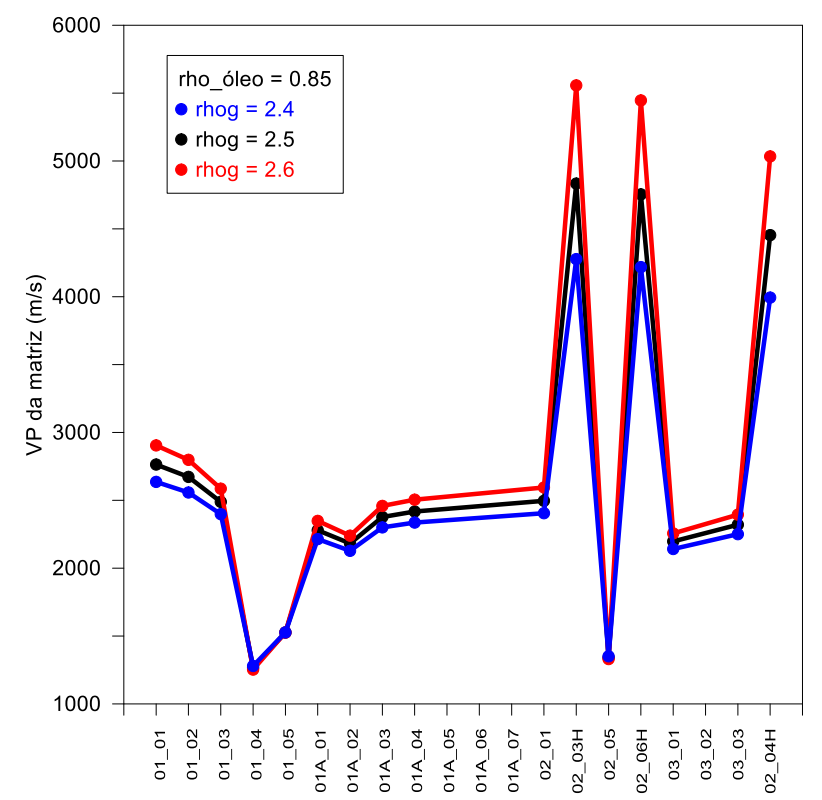

Figura 15 - Estimativa da VP da matriz considerando po $=0,85 \mathrm{~g} / \mathrm{cm}^{3}$ e variando $\rho_{\mathrm{GR}}$ entre 2,4 e $2,6 \mathrm{~g} / \mathrm{cm}^{3}$.

A Figura 16 apresenta a velocidade da onda $P$ medida nas amostras naturalmente saturadas com óleo e a estimada para amostras secas. A pressão confinante é de $20 \mathrm{MPa}, \rho_{\mathrm{GR}}=2,5 \mathrm{~g} / \mathrm{cm}^{3}$ e $\rho \mathrm{o}=0,85 \mathrm{~g} / \mathrm{cm}^{3}$. Vê-se que há um considerável efeito da saturação sobre a velocidade da onda $P$.

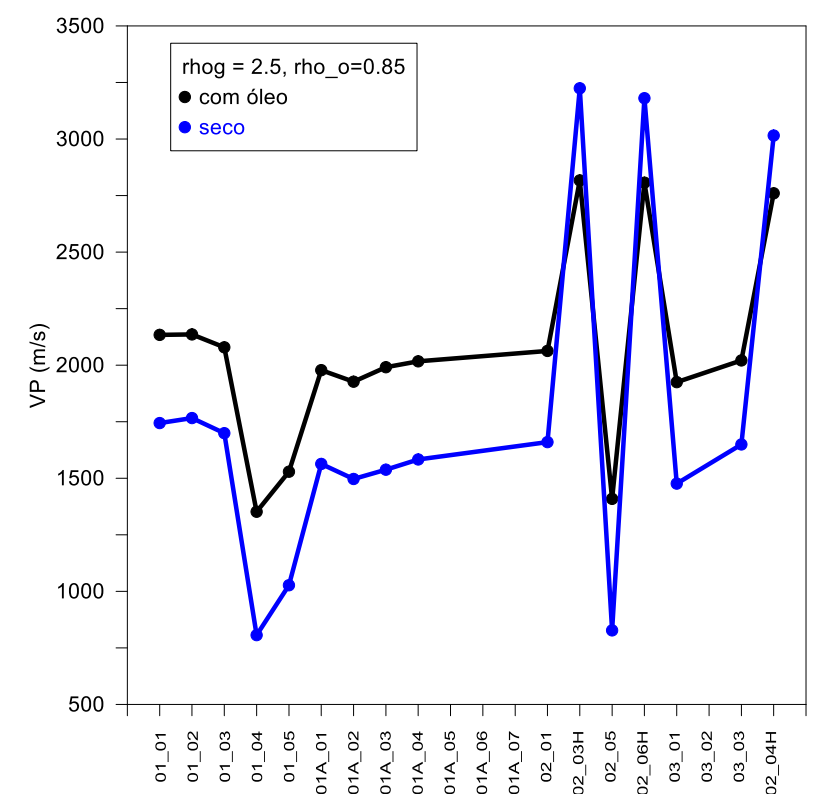

Figura 16 - VP das amostras saturadas com óleo e secas. Pconf $=20 \mathrm{MPa}, \rho_{\mathrm{GR}}=2,5 \mathrm{~g} / \mathrm{cm}^{3}$ e $\rho_{\mathrm{O}}=0,85$ $\mathrm{g} / \mathrm{cm}^{3}$.

\section{Conclusões}

Devido à saturação natural de óleo e, provavelmente, à presença de matéria orgânica, nos folhelhos negros a densidade de grãos e a porosidade medidas são aparentes. Tal fato explica o comportamento inesperado entre a densidade de grãos, a densidade total e a porosidade medidas.

A velocidade da onda $P$ contra pressão confinante mostra que há três grupos de amostras: as amostras horizontais, que são as de mais alta velocidade, um grupo de velocidades mais baixas, que possuem maior saturação de óleo e, possivelmente, maior teor de matéria orgânica, e um grupo com velocidades intermediárias, composto pelas demais amostras verticais. Não se observa a esperada relação decrescente das velocidades elásticas com o aumento da porosidade medida. A anisotropia de VS é limitada a $20 \%$, independente da direção da amostra e da saturação em hirdrocarboneto.

Neste trabalho é proposto um método para a estimação da saturação de óleo em folhelhos negros e correção do efeito dessa saturação sobre as propriedades petrofísicas medidas. Assumindo que a densidade de grãos varia entre 2,4 e $2,6 \mathrm{~g} / \mathrm{cm}^{3}$ e que a densidade do óleo varia entre 0,8 e $0,9 \mathrm{~g} / \mathrm{cm}^{3}$, mostrou-se que a porosidade verdadeira, a saturação de óleo e a velocidade acústica da matriz dependem, de forma decrescente, do valor da densidade de grãos. O efeito da densidade do óleo, dentro do intervalo de valores assumido, foi desprezível, exceto para a estimativa da porosidade real. Através do método proposto foi possível estimar, também, a velocidade da onda $P$ das amostras secas, ou seja, excluindo o efeito da saturação parcial de petróleo.

Trabalhos futuros incluem análise geoquímica dessas amostras de folhelho e do óleo extraído delas, bem como a determinação da densidade real dos grãos e da porosidade verdadeira através da análise digital de imagens de microtomografia de raios $x$.

\section{Referências}

ASSINE, M. L. (1992). Análise estratigráfica da Bacia do Araripe, Nordeste do Brasil. Revista Brasileira de Geociências, 22 (3) : 289-300.

NEUMANN, V. H.; BORREGO, A. G.; CABRERA, L.; DINO, R. (2003). Organic matter composition and distribution through the Aptian-Albian lacustrine sequences of the Araripe Basin, northeastern Brazil. International Journal of Coal Geology 54, 21- 40.

CATTO, B. (2015). Laminitos microbiais no membro Crato (neoaptiano), Bacia do Araripe, nordeste do Brasil. Dissertação de mestrado. Instituto de Geociências e Ciências Exatas da Universidade Estadual Paulista, Campus de Rio Claro. 